\title{
Os outros do futuro e a ética da responsabilidade ambiental.
}

The other of the future and the ethics of environmental responsibility.

\section{Telma Maria Santos Machado ${ }^{1}$}

\section{RESUMO}

Somos responsáveis, na lição do filósofo alemão Hans Jonas pelos que ainda não existem, pelas formas de vidas que ainda virão, pela evolução que estas formas adquirirão, pela existência futura, mas também pela impossibilidade dela em face das transformações a que submetermos o planeta.

Palavras Chaves: Ética. Responsabilidade Ambiental. Hans Jonas.

\section{ABSTRACT}

We are responsible, the lesson of the German philosopher Hans Jonas those who do not yet exist, the forms of life yet to come, by the evolution that these forms will acquire, the future existence, but also by her inability to face the changes they submit the planet.

Key Words: Ethics. Environmental Responsibility. Hans Jonas.

Hans Jonas traduz este momento delicado pelo qual temos passado já há várias décadas quando, partindo do imperativo categórico de Kant "aja de tal modo que tu também possas querer que tua máxima se torne lei geral”, ensina que um "imperativo adequado ao novo agir humano e voltado para o novo tipo de sujeito atuante deveria ser assim expressado: ‘Aja de tal modo que os efeitos da tua ação sejam compatíveis com a permanência de uma autêntica vida humana na Terra’; ou, exposto negativamente: ‘aja

\footnotetext{
${ }^{1}$ Mestre em Filosofia | UFS, Graduada em Ciências Biológicas e em Direito, pós-graduada em Direito Processual Público, ex-Auditora de tributos estaduais, ex-Promotora de Justiça, ex-Procuradora da República, Juíza Federal desde 1999.
} 
de modo a que os efeitos da tua ação não sejam destrutivos para a possibilidade futura de tal vida'."2

Amplia-se, portanto, o foco da ética para tempos distantes, lá no futuro, e isso demanda uma mudança de comportamento, que, inicialmente, deve buscar o conhecimento necessário a fim de que se possa assimilar o fato de sermos partes integrantes de um sistema vivo impressionantemente rico e belo e que, sendo os maiores responsáveis por uma eventual futura inexistência do mesmo, somos, por outro lado e felizmente, também habilitados para dizer sim à vida e à existência dos que ainda virão.

\section{DESENVOLVIMENTO.}

A ética da responsabilidade proposta por Hans Jonas sem dúvida clama para a necessidade de se lançar novo, profundo e respeitoso olhar sobre a natureza, o que não significa o esquecimento ou a indiferença às necessidades humanas, mas sim traduzindo-se como um grito preventivo, um apelo à ponderação de interesses. Como enfatiza Jacqueline Russ, "Este levar em conta ecológico das mutações do agir humano e da realidade natural é legítimo, como a vontade de inscrever os problemas do meio ambiente no coração das preocupações éticas”3 ${ }^{3}$. Um sim à vida equivale - a menos que o planeta seja sacudido por desastres sobre os quais não tenhamos qualquer interferência ou poder de prevenção - a um sim à futura existência do gênero humano; e sempre que existam humanos, nós, de certa forma, existiremos também, porque compartilhamos a humanidade que nos é cogente.

Sendo induvidoso que parte da humanidade tergiversa em assumir responsabilidades, bastas vezes atribuindo-as a governos (que também as tem), a entes encarregados de fiscalização e de punição, há de se refletir com mais vigor que pequenas ações individuais, geralmente invisíveis para que sejam repreendidas ou

\footnotetext{
2 JONAS, Hans. O princípio responsabilidade. Tradução de Marijane Lisboa e Luiz Barros Montez. Rio de Janeiro: PUC, 2006, p. 47/48.

${ }^{3}$ RUSS, Jacqueline. Pensamento ético contemporâneo. Tradução de Constança Marcondes Cesar. São Paulo: Paulus, 1994, p. 156.
} 
penalizadas, quando somadas adquirem uma capacidade deletéria que sequer se pode aquilatar, por não se deter ainda conhecimento suficiente das consequências em nível de ciclo biológico. Daí porque a advertência de Jonas é irreprochável: “Tanto o conhecimento quanto o poder eram por demais limitados para incluir o futuro mais distante em suas previsões e o globo terrestre na consciência da própria causalidade”4.

Os não nascidos não têm como se defender das ações que podem inviabilizar a existência deles, daí porque precisamos nos revestir da ética da responsabilidade a fim de lhes garantir a oportunidade que nos foi dada: de ser, de existir.

Neste momento grave, a Filosofia necessita ouvir outras ciências, especialmente a Biologia, a fim de se possibilitar uma discussão sem abstração da situação biológica que se apresenta independentemente do querer filosófico, eis que as condições planetárias e os seres vivos, com exceção do homem, não se comportam pautados por agir ético: refletem a causalidade do que lhe fizerem e somente indiretamente, por sofrer as consequências das ações humanas, terá relação com a ética.

Jonas se refere eloquentemente a esta premente necessidade de os vários ramos do conhecimento, além da filosofia, dialogarem na questão ambiental, justamente porque são eles que podem responder, ainda que sem total segurança, como a natureza reagirá a agressões cada vez mais intensificadas ${ }^{5}$, ou seja:

\begin{abstract}
Essa questão situa-se no domínio de saber da jovem ciência ecológica e, em particular, nas áreas de conhecimento de biólogos, agrônomos, químicos, geólogos, climatologistas e outros, além de economistas e engenheiros, de urbanistas e especialistas em transportes, cuja colaboração interdisciplinar conduz à ciência ecológica de que hoje necessitamos. Aqui o filósofo nada tem a dizer, apenas a ouvir ${ }^{6}$. Lamentavelmente, a ciência atual não é capaz de lhe oferecer resultados seguros. Todas as predições quantitativas nos diversos campos do saber ainda são incertas, para não falar da sua integração em um todo ecológico, na suposição de que elas possam ser passíveis de cálculo matemático. De toda forma, é possível indicar em vários casos o tipo de limites existentes $(\ldots)^{7}$.
\end{abstract}

\footnotetext{
${ }^{4}$ JONAS, Hans. O princípio responsabilidade. Tradução de Marijane Lisboa e Luiz Barros Montez. Rio de Janeiro: PUC, 2006, p. 22.

${ }^{5}$ JONAS, Hans. Op. cit, p. 300.

${ }^{6}$ Original sem negrito.

${ }^{7}$ JONAS, Hans. Op. cit, p. 301.
} 
Evidentemente quando Hans Jonas diz que o filósofo "nada tem a dizer”, há de se entender que ele se refere ao aspecto técnico de cada ciência, cujo conhecimento requer formação específica. Mas não está e nem poderia excluir a Filosofia da discussão, da reflexão acerca da contribuição e das consequências éticas das descobertas destas ciências.

Tal aspecto não passou despercebido por Jaqueline Russ, que o comenta em sua obra já mencionada, na parte referente às éticas aplicadas. Logo na introdução a autora lança a instigante indagação “Grandeza ou miséria das éticas aplicadas?”, sobre a qual ela trará importantes apontamentos, a exemplo dos seguintes:

Onipresentes, reivindicadas tanto no seio da empresa quanto nos comitês médicos, as éticas aplicadas aos diferentes campos sociais e científicos nem sempre têm boa circulação junto aos pensadores. Contudo, a ideia de partir de princípios e retornar às diversas esferas - ciências biológicas ${ }^{\mathbf{8}}$, mídias, mundo dos negócios etc. - parece, a priori, perfeitamente legítima. Toda prática exige o recurso a normas ou princípios destinados a esclarecer a ação. A descida outra vez “à caverna”, no nosso universo empírico, de modo a guiar os comportamentos, não parece aqui um procedimento gratuito. Por que, pois, esta crítica frequente às éticas aplicada? ${ }^{9}$

E na conclusão da parte referente a tais éticas, Russ assim verbera:

Contrariamente a certas idéias em voga, não se pode ver nas éticas aplicadas deontologias axiológicas, pondo em jogo princípios de responsabilidade e de comunicação? Irredutíveis às metamorais teóricas, as éticas aplicadas não são, contudo, novidades. Exprimem, de maneira frequentemente confusa, a desordem de uma tempo que, na ausência de referências fixas, esforça-se sem tomar o futuro a seu encargo. Às vezes submetidas às modas do momento, supõem, contudo, um certo "retorno da moral", numa época nutrida por inquietudes difusas e por angústias, concernentes ao ad-vir distante do homem $^{10}$

De fato, nem a Filosofia pode menosprezar o que é fato comprovado ou dedutível em face da causalidade, nas diversas áreas das ciências, nem as ciências prescindem da reflexão filosófica sobre tais fatos, especialmente quando eles se referem ou se relacionam, ainda que indiretamente, com o ser humano. Daí a pertinência da

\footnotetext{
${ }^{8}$ Original sem negrito.

${ }^{9}$ RUSS, Jacqueline. Op. cit., p. 135.

${ }^{10}$ Id., ibid., p. 168.
} 
observação de Jacqueline Russ quanto aos perigos de se criar um “cientismo”, irmão gêmeo do positivismo, que "oculta a especificidade humana ou o núcleo axiológico dos problemas”"11. Eis que, assevera a autora, constituir um estudo do homem sem esse último, negando sua especificidade, ou seja, o projeto humano que informa o corpo e a vida, fazendo a economia da reflexão sobre a pessoa, cientismo e positivismo ocultam o essencial, as normas éticas, os princípios fundadores, a axiologia que deve esclarecer a bioética, como retomada reflexiva e não como deontologia, isto é, o cientismo longe de ser ciência, designa a ciência entregue a si mesma e querendo legislar em tudo ${ }^{12}$.

Essas observações são relevantes especialmente para que se possa analisar até que ponto haveria no apelo ético de Hans Jonas uma heurística do temor decorrente apenas de um mal imaginado ou de um mal provável, à luz do que já se tem como fato científico ou como perspectiva decorrente de causalidade biológica respaldada pelos conhecimentos atuais. Isto parece ter sido bem compreendido na ponderação a seguir transcrita.

Ao operar com essa crítica às éticas da tradição, ao contrário do que pode parecer, Jonas não visa a substituí-la ou mesmo a eliminá-las. Nesse sentido, o princípio responsabilidade poderia ser visto como um complemento ou, até mesmo, como atualização da ética, na medida em que os problemas de nosso tempo exigem mais elementos e considerações do que a tradição tem para oferecer.

Por isso mesmo é que se apresenta a exigência de um trabalho científico interdisciplinar que extrapole o próprio âmbito restrito da ética filosófica, conclamando todas as ciências à colaboração para o estabelecimento de um novo patamar de relações, de uma nova posição sobre os problemas técnicocientíficos. Se Jonas tem razão, então a filosofia contemporânea não pode mais se esquivar dessa tarefa, pois não está em condições de resolvê-la sozinha ${ }^{13}$.

E em resposta a alguns críticos que veem na fala de Jonas uma admoestação terrificante, desarrazoada, Santos alinhava da seguinte forma:

\footnotetext{
${ }^{11}$ RUSS, Jacqueline. Op. cit, p. 150.

12 Id., ibid., p. 151.

13 SANTOS, Robinson dos. Ética para a civilização tecnológica: em diálogo com Hans Jonas. Coordenadores Robinson dos Santos, Jelson Oliveria, Lourenço Zancanaro. 1. Ed. São Paulo: Centro Universitário São Camilo, 2011, p. 37.
} 
Cumpre assinalar, por fim, que Jonas não calca suas admoestações em uma postura alarmista ou caprichosamente pessimista, apesar de dar margem para essa forma de interpretação de sua ética, sobretudo se sua heurística do temor for entendida enquanto uma apologia do medo, isto é, de que o sentimento patológico seria suficiente para mobilizar os seres agentes. Jonas não ser refere a esse tipo de comportamento, mas faz um apelo à razão técnica (ou instrumentalizada) para que, como na época de Kant, compareça ao tribunal e submeta-se ao julgamento $^{14}$.

\section{CONCLUSÃO.}

A ética da responsabilidade voltada para um futuro até longínquo é uma ampliação da ética clássica, e parte de uma análise crítica das ações atuais em face das condições também atuais, cuja projeção para o futuro, por uma causalidade perceptível a partir do conhecimento específico já apropriado, impõe um dever de agir em prol do Ser e do Existir no futuro.

Um projeto ético de tal envergadura exige um amplo e profundo diálogo entre os diversos ramos do saber científico e não prescinde, nem poderia (porque está a se falar do agir ético da humanidade atual em prol da vida, aí incluída a humana), da participação da Filosofia neste debate de valores, de escolhas, de atitudes.

\section{REFERÊNCIAS.}

CHEDIAK, Karla. Filosofia da biologia. Rio de Janeiro: Jorge Zahar Ed., 2008.

JONAS, Hans. O princípio responsabilidade. Tradução de Marijane Lisboa e Luiz Barros Montez. Rio de Janeiro: PUC, 2006.

RUSS, Jacqueline. Pensamento ético contemporâneo. Tradução de Constança Marcondes Cesar. São Paulo: Paulus, 1994.

\footnotetext{
${ }^{14}$ Id., ibid., loc. cit.
} 
ISSN ELETRÔNICO 2316-8080

OS OUTROS DO FUTURO E A ÉTICA DA RESPONSABILIDADE AMBIENTAL.

SANTOS, Robinson dos. Ética para a civilização tecnológica: em diálogo com Hans

Jonas. Coordenadores Robinson dos Santos, Jelson Oliveria, Lourenço Zancanaro. 1. Ed. São Paulo: Centro Universitário São Camilo, 2011.

Publicado no dia $24 / 10 / 2014$

Recebido no dia 08/10/2014

Aprovado no dia 09/10/2014 